\title{
Experimental study of low-cycle fatigue of pipe elbows with local wall thinning and life estimation using finite element analysis
}

Koji Takahashi, Satoshi Tsunoi, Takumi Hara, Tomohiro Ueno, Akira Mikami, Hajime Takada, Kotoji Ando and Masaki Shiratori

\author{
Faculty of Engineering, \\ Yokohama National University, \\ 79-5, Tokiwadai, Hodogaya, Yokohama, 240-8501, Japan
}

Correspondence:

Dr. Koji Takahashi

Faculty of Engineering,

Yokohama National University,

79-5, Tokiwadai, Hodogaya, Yokohama, 240-8501, Japan.

E-mail:ktaka@ynu.ac.jp 


\section{ABSTRACT}

Low-cycle fatigue tests were conducted using elbow specimens with local wall thinning. Local wall thinning was machined on the inside of the elbow in order to simulate metal loss from erosion corrosion. The local wall thinning was located in three different areas known as the extrados, crown and intrados. The elbow specimens were subjected to cyclic in-plane bending under displacement control without internal pressure. In addition, three-dimensional elastic-plastic analyses were also carried out using the finite element method. As a result, the crack penetration area and the crack growth direction were successfully predicted by the analyses. The fatigue lives estimated by the analyses were close to those obtained by the experiments.

Keywords: Wall thinning; Elbow; Low-cycle fatigue; Carbon steel pipe; Finite element analysis

\section{INTRODUCTION}

Carbon steel pipes are commonly used in the piping systems of power plants. Erosion corrosion can cause wall thinning due to high-temperature and high-pressure water and steam flowing at high velocities through these pipes. Therefore, it is important to evaluate the strength of piping undergoing local wall thinning in order to maintain the integrity of the piping systems. Several experimental and analytical studies have been performed with the aim of developing a methodology for evaluating the integrity of piping undergoing wall thinning $[1,2,3]$. Full-scale pipe tests were carried out for straight pipes [4], tees [5] and orifices [6], and analytical models for evaluating the integrity of wall-thinned piping systems were proposed. Most of these studies are monotonic tests.

Power plant piping is designed to withstand seismic events. It is important to establish a method to estimate the safety margin of degraded pipes against seismic loading. A series of large-scale experiments on this topic was carried out under the "New Aged-Piping Committee" sponsored by the 
National Research Institute for Earth Science and Disaster Prevention (NIED). The results of this research have been reported in detail [7].

The wall thinning that occurs due to erosion corrosion is exacerbated at elbows. Some researchers have studied static and fatigue strength of elbows with local wall thinning $[8,9]$. However, the low-cycle fatigue strength of elbows with local wall thinning is not yet clear. The number of experiments on this topic is limited because they are expensive, laborious, and time consuming. It is preferable to establish an analytical approach to simulate the experimental procedure.

Shiratori et al. proposed an analytical model by which the failure of degraded piping under seismic loading can be estimated reasonably. A series of finite element analyses was performed for a 3D piping system under seismic loading [7]. It was shown that the proposed analytical models can describe experimental behaviors such as ratcheting, buckling and penetration of a surface crack through the wall thickness.

In this paper, in order to investigate the low-cycle fatigue behaviors of elbows undergoing local wall thinning, low-cycle fatigue tests were carried out using elbow specimens with local wall thinning. Section 2 describes the experimental results for testing the low-cycle fatigue behaviour of elbows under in-plane bending without internal pressure, and the local wall thinning introduced at the extrados, crown and intrados. Then Section 3 presents the results of finite element analyses carried out to simulate the tests. The results are compared to the experimental data leading to the conclusions presented in Section 4.

\section{EXPERIMENTS}

\subsection{Experimental procedures}

The elbow specimens used in the experiments were carbon steel pipes known as "carbon steel pipes for high temperature," STS410 in JIS (Japanese Industrial Standards), which are used in the 
class 2 piping of nuclear power plants in Japan. Yield strength and tensile strength are $312 \mathrm{MPa}$ and $470 \mathrm{MPa}$, respectively. The nominal outer diameter is $114.3 \mathrm{~mm}$ and the nominal thickness is 8.6 mm. Figure 1(a) shows the shape and geometry of the elbow specimens. Figure 1(b) shows the position and dimensions of the local wall thinning. Table 1 shows the conditions of the eroded sizes of the elbow pipe specimens. Four elbow specimens were used in this study. The local wall thinning was machined on the inside of the pipes to simulate erosion corrosion metal loss. In this paper, the eroded sections were located in three different areas, known as the extrados, crown and intrados. A sound elbow specimen without an eroded area was also used. The elbow specimens were labeled "sound," "extrados," "crown" and "intrados," respectively. The depth of metal loss in the thickness direction is called the eroded depth $(d)$. The eroded ratio is defined as the ratio of $d$ to the wall thickness $t(d / t)$ and was fixed at $d / t=0.5$. The eroded angle $(2 \theta)$ is the circumferential wall thinning angle and was fixed at $2 \theta=90^{\circ}$. The eroded length $(l)$ is the length of the wall thinning in the axial direction and was fixed at $l=100 \mathrm{~mm}$.

Figure 2 shows the experimental apparatus and elbow specimens. The low-cycle fatigue tests were conducted using a universal testing machine $(250 \mathrm{kN})$ at room temperature without internal pressure. The elbow specimens were subjected to cyclic in-plane bending under displacement control. The loading frequency was $0.1 \mathrm{~Hz}$. The relative opening-and-closing displacements $\delta$ between the two ends are an important factor in controlling fatigue life. Prior to the experiments, we carried out preliminarily finite element analysis to determine the value of $\delta$. The number of cycles considered in the experimental seismic event was less than 100. As a result of the analysis, the value of $\delta$ was determined to be $\pm 30 \mathrm{~mm}$.

In the experiments, we measured and evaluated the relationship between load and displacement, the time history of the strain, the crack initiation point, the direction of the crack, and fatigue life $\left(N_{f}\right)$. In this study, $N_{f}$ is defined as the number of cycles of bending until crack penetration occurred. 


\subsection{Experimental results}

Figure 3 shows photographs of the elbow specimens after low-cycle fatigue tests showing the crack penetration site.

In the sound pipe, a crack penetrated and propagated in the longitudinal direction at the crown as shown in Fig. 3(a). The fatigue life of the sound pipe was $N_{f}=87$. At the other side of the crown, only an axial line was observed, and crack penetration did not occur as shown in Fig. 3(b).

In the extrados pipe, an axial line occurred at the crown as shown in Fig. 4(a). A crack then penetrated and propagated in the longitudinal direction as shown in Fig. 4(b). The fatigue life of the extrados pipe was $N_{f}=88$, which was similar to that of the sound pipe.

In the crown pipe, an axial line occurred at the crown where the local wall thinning existed as shown in Fig. 5(a). Then, a crack penetrated and propagated in the longitudinal direction as shown in Fig. 5(b). The fatigue life of this pipe was $N_{f}=77$, which was smaller than those of the sound and extrados pipes.

In the intrados pipe, a crack initiated at the outer surface of the intrados as shown in Fig. 6(a). The crack then penetrated and propagated along the hoop direction. The fatigue life of this pipe was $N_{f}=61$, which was the smallest among the elbow pipes tested in this study.

On the basis of the crack penetration behavior, it appears that the crack initiation point in the sound, extrados and crown pipes was the inner surface of the crown and that in the intrados pipe it was the outer surface of the intrados.

\section{ANALYSIS}

\subsection{Finite element analysis}

Elastic-plastic analyses of the elbow specimens were performed. The software codes used in the analyses were Excel and Hyper Mesh for generating the finite element model and element breakdown, ABAQUS as the solver, and ABAQUS VIEWER for post-processing. 
Elbow specimens including attached straight pipes were modeled using 8-node solid elements; this model has 11208 nodes and 8720 elements. Figure 7 shows a finite element model of the elbow pipe and the eroded area. Figure 8 shows the relationship between true stress and true strain in carbon steel STS410. A bilinear stress-strain curve was assumed in the analysis, where

$\begin{array}{ll}\text { Young's modulus } & E=203 \mathrm{GPa} \\ \text { Poisson's ratio } & v=0.3 \\ \text { Yield stress } & \sigma_{y}=424 \mathrm{MPa} \\ \text { Second slope } & S^{\prime}=1200 \mathrm{MPa} .\end{array}$

A linear kinematic hardening rule was assumed to simulate the ratcheting behavior of materials. The yield stress used in the analysis is higher than that mentioned in section 2.1. This is because the test material is susceptible to cyclic hardening. The relative opening-and-closing displacements between the two ends of the elbow were $\pm 30 \mathrm{~mm}$. The analyses were carried out over up to 50 cycles of loading.

We analyzed the time history of the strain and the distribution of equivalent plastic strain.

\subsection{Estimation of fatigue lives}

In order to estimate the low-cycle fatigue lives with the ratchets, Nakamura et al. [7] made use of two approaches, one based upon Miner's rule and the other based upon Asada's experimental formula [11]. For the carbon steel used in the present experiment, the characteristic of low-cycle fatigue tests is expressed by [10]

$$
\Delta \varepsilon_{t}=0.6158 N_{f}^{-0.0746}+89.08 N_{f}^{-0.5414}
$$

for room temperature, where $\Delta \varepsilon_{t}$ is the applied total strain amplitude and $N_{f}$ is the number of cycles performed until the rupture. If the applied strain amplitude changes, the fatigue damage $\eta$ is defined by

$$
\eta=\sum_{i=1}^{n} \frac{N_{i}}{N_{f i}}
$$


where $N_{i}$ and $N_{f i}$ are the number of cycles actually applied in the present analysis and the number corresponding to the failure, respectively, for the applied amplitude $\Delta \varepsilon_{t i}$. Then Miner's rule is described such that the low-cycle fatigue life can be estimated by the criterion of

$$
\eta=1 .
$$

On the other hand, Asada et al. proposed the following approach [11] such that

$$
F=D_{f}+2 \sqrt{D_{f} D_{d}}+D_{d}=1,
$$

where

$$
\begin{array}{ll}
F & : \text { fatigue factor, } \\
D_{f}=\eta^{0.6} & : \text { fatigue damage, } \\
D_{d}=\varepsilon_{f} / \varepsilon_{f_{0}} & : \text { ductility consumption, } \\
\varepsilon_{f_{0}}=\ln \frac{100}{100-\varphi} & : \begin{array}{c}
\text { true rupture ductility } \\
(\varphi \text { :reduction in area }) .
\end{array}
\end{array}
$$

By applying the above equation, the fatigue life at crack penetration can be estimated reasonably $[7,12]$.

\subsection{Calculation method of fatigue lives under multi-axial strain}

The elbow pipes were subjected to multi-axial stress and strain. Thus, the multi-axial stress and strain should be considered when the fatigue lives are evaluated. In this section the fatigue life evaluation method mentioned above is extended to the case of a multi-axial strain state. There are many approaches to the prediction of fatigue behavior and fatigue life, some of which use equivalent strain range [13]. In this study, the fatigue life is evaluated based on the maximum principal strains range because of the simplicity of the analysis. Also, this model gives reasonable predition results [7,12]. As shown in Fig. 9, the local coordinates $x^{\prime}-y^{\prime}$ are introduced into each element that constitutes the FEM model. The $\mathrm{x}^{\prime}$ axis is set up in the direction of the flow in the pipes, and the $\mathrm{y}^{\prime}$ 
axis is at right angles to the $\mathrm{x}^{\prime}$ axis. The angle $\theta$ is measured clockwise from the $\mathrm{x}^{\prime}$ axis. The nominal strains $\varepsilon_{x}, \varepsilon_{y}$, and $\gamma_{x y}$ are transformed into $\varepsilon_{\theta}$ with

$$
\begin{aligned}
\varepsilon_{\theta} & =\varepsilon_{x} \cos ^{2} \theta+\varepsilon_{y} \sin ^{2} \theta+\gamma_{x y} \cos \theta \sin \theta \\
& =\frac{\varepsilon_{x}+\varepsilon_{y}}{2}+\frac{\varepsilon_{x}-\varepsilon_{y}}{2} \cos 2 \theta+\gamma_{x y} \sin 2 \theta
\end{aligned}
$$

The total strain range $\Delta \varepsilon(\theta)$ and the cumulative strain $\varepsilon_{f}(\theta)$ are calculated in each angle direction using Eq. (8). Then, the fatigue damage $D_{f}(\theta)$ and ductility consumption $D_{d}(\theta)$ are calculated using Eq. (5) and Eq. (6), respectively. As a result, the relationship between $F(\theta)$ and the angle at the most strain-concentrated area is evaluated. We assumed that the crack propagates in a direction perpendicular to the direction where $F$ has the maximum value.

\subsection{Analytical results}

Figure 10 shows a contour figure of equivalent plastic strain at the inner or outer surface for each specimen. The most strain-concentrated points are shown by circles. In sound and crown pipes, the most strain-concentrated point occurred at the inner surface of the crown as shown in Figs. 10(a) and 10(c). In extrados pipe, the most strain-concentrated point occurred at the inner surface of the crown as shown in Fig. 10(b), regardless of wall thinning at the extrados. In the intrados specimen, the most strain-concentrated point occurred at the outer surface of the intrados as shown in Fig. $10(d)$.

Figure 11 shows the strain history at the most strain-concentrated point. Both hoop and axial strain occurred. Thus, a fatigue life estimation based on multi-axial strain is necessary, as mentioned above. In sound, extrados and crown specimens, the hoop strain is larger than the axial strain. In intrados pipes, the axial strain is larger than the hoop strain.

Figure 12 shows the estimation of the low-cycle fatigue factor $(F)$ as a function of the angle $\theta$ at the most strain-concentrated point after the elbow specimens were subjected to 50 cycles of loading for each specimen. In sound, extrados and crown specimens, the $F$-value reaches a maximum at 
around $90^{\circ}$. It can be predicted that crack propagation occurs in the longitudinal direction in these specimens. In intrados pipes, the $F$-value reaches its maximum at around $0^{\circ}$ or $180^{\circ}$. It can be predicted that crack propagation occurs in the hoop direction in the intrados pipe.

\subsection{Comparison with experimental results}

Table 2 compares the crack penetration area and direction of crack propagation determined by the experiments with those determined by the analyses. The experimental and analytical results are coincident in every elbow specimen. Thus, it can be said that the crack penetration area and the direction of crack propagation can be successfully predicted by the analysis.

Figure 13 shows a comparison of the low-cycle fatigue factor $(F)$ among the specimens. The maximum $F$-values at the outer and inner surfaces are shown in the left and right columns, respectively, for each specimen. Here, we assumed that the $F$-value increases linearly with the number of cycles, and the crack penetration occurs when the largest $F$ value reaches 1 . This prediction is based on linear extrapolation of the rate of damage accumulation. Thus, the fatigue life $N_{f}$ is caluculated by $50 /$ F. From these assumptions, we can predict the number of cycles performed until crack penetration occurs.

Figure 14 shows the number of cycles until failure occurs as determined by the experiments and the analysis. The fatigue lives estimated by the analyses are shown on the left, and the experimental results are shown on the right. Comparing the experimental results and analytical results, it can be said that the number of cycles until crack penetration occurs can be successfully predicted by the analysis. 


\section{CONCLUSIONS}

Low-cycle fatigue tests were conducted using elbow specimens with local wall thinning. The local wall thinning was located in three different areas, known as the extrados, crown and intrados. The elbow specimens were subjected to cyclic in-plane bending under displacement control without internal pressure. In addition, three-dimensional elastic-plastic analyses were also carried out using the finite element method. The conclusions obtained are as follows.

(1) If the local wall thinning was located at the extrados or crown, the crack was initiated at the inner surface of the crown and propagated in the longitudinal direction. These failure behaviors were quite similar to those of the sound specimen. The fatigue lives of extrados and crown pipes were almost the same as that of the sound pipe. Thus, the local wall thinning introduced in this study $\left(d / t=0.5\right.$ and $\left.2 \theta=90^{\circ}\right)$ did not affect the low-cycle fatigue behavior if it was located at the extrados or crown.

(2) If the local wall thinning was located at the intrados, the crack was initiated at the outer surface of the intrados and propagated in the hoop direction. This failure behavior was different from that of the sound pipe. The fatigue life of the intrados pipes was shorter than that of the sound pipe. Thus, attention should be paid to whether the local wall thinning is located at the intrados.

(3) The crack penetration area and the crack growth direction were successfully predicted by the analyses. The fatigue lives estimated by analysis were close to those obtained by experiment.

\section{ACKNOWLEDGMENTS}

This study was performed under the sponsorship of JNES open application research project for enhancing the basis of nuclear safety. (JNES: Japan Nuclear Energy Safety Organization). The authors thank Dr. A. Otani from IHI for specimen preparation and Dr. I. Nakamura from NIED for helpful discussions. 


\section{REFERENCES}

[1] Japan Atomic Energy Research Institute, 1993, Technical report on the piping reliability tests at the Japan Atomic Energy Research Institute. 1993, No.93-076, JAERI-M, p. 104-115. (in Japanese)

[2] Roy S, Grigory M, Smith, M., Kanninen MF, Anderson M. Numerical simulations of full-scale corroded pipe tests with combined loading. J. Press. Vessel Technol 1997;119: 457-466.

[3] Mathonet JF, Cherasse JM, Leblois CL, Guyette MA. Belgian methodology for evaluation of erosion corrosion phenomena in units 1, 2, $3 \& 4$ of the Doel nuclear power plant. ASME PVP 1995;303:393-399.

[4] Miyazaki K, Kanno S, Ishiwata M, Hasegawa K, Ahn SH, Ando K. Fracture behavior of carbon steel pipe with local wall thinning subjected to bending load. Nucl. Eng. Des. 1999;191:195204.

[5] Takahashi K, Kato A, Ando K, Hisatsune M, Hasegawa K. Fracture and deformation behaviors of tee pipe with local wall thinning. Nucl. Eng. Des. 2005;237:137-142.

[6] Takahashi A, Ando K, Hisatsune M, Hasegawa K. Failure behavior of carbon steel pipe with local wall thinning near orifice. Nucl. Eng. Des. 2005;237:335-341.

[7] Nakamura I, Otani A, Shiratori M. A study on fracture mechanics of eroded pipes under seismic loading. Technical Note of the National Research Institute for Earth Science and Disaster Prevention 2007, No.306, NIED, Japan (in Japanese).

[8] Ahn SH, Nam KW, Yoo YS, Ando K, Ji SH, Ishiwata M, Hasegawa K. Fracture behavior of straight pipe and elbow with local wall thinning. Nucl. Eng. Des. 2002;211:91-103.

[9] Kim JW, Na MG, Park CY. Effect of local wall thinning on the collapse behavior of pipe elbows subjected to a combined internal pressure and in-plane bending load. Nucl. Eng. Des., 208;238:1275-1285.

[10] NUPEC report on reliability proof tests of nuclear power plant against seismic loading, No.3 ultimate strength of piping. 2000, Nuclear Power Engng. Corp. (in Japanese).

[11] Namaigawa J, Ueno K, Ishikawa A, and Asada Y. Life prediction technique for ratcheting fatigue, creep, fatigue evaluation, and leak before break assessment, ASME PVP 1993;266:3-11.

[12] Shiratori M, Ochi Y, Nakamura I and Otani A. Failure analysis on thinned wall elbows under excessive seisemic loading, ASME PVP 2002;455-1:7-16.

[13] The Society of Materials Science Japan, Data Book for Fatigue Design, 1993, p.104, Yokendo, Tokyo (in Japanese). 
Table 1 Test conditions for elbow specimens with local wall thinning.

\begin{tabular}{|c|c|c|c|}
\hline $\begin{array}{c}\text { Specimen } \\
\text { name }\end{array}$ & Eroded part & $\begin{array}{c}\text { Eroded ratio } \\
d / t\end{array}$ & $\begin{array}{c}\text { Eroded angle } \\
2 \theta\end{array}$ \\
\hline Sound & - & - & - \\
\hline Extrados & Extrados & 0.5 & $90^{\circ}$ \\
\hline Crown & Crown & 0.5 & $90^{\circ}$ \\
\hline Intrados & Intrados & 0.5 & $90^{\circ}$ \\
\hline
\end{tabular}


Table 2 Failure behavior of elbow pipes in experiments and analysis.

\begin{tabular}{|c|c|c|c|c|}
\hline \multirow[b]{2}{*}{$\begin{array}{l}\text { Specimen } \\
\text { name }\end{array}$} & \multicolumn{2}{|c|}{ Experimental results } & \multicolumn{2}{|c|}{ Analytical results } \\
\hline & $\begin{array}{c}\text { Crack } \\
\text { penetration } \\
\text { area }\end{array}$ & $\begin{array}{l}\text { Direction } \\
\text { of crack }\end{array}$ & $\begin{array}{c}\text { Crack } \\
\text { penetration } \\
\text { area }\end{array}$ & $\begin{array}{l}\text { Direction } \\
\text { of crack }\end{array}$ \\
\hline \multirow{2}{*}{ Sound } & Inner surface & \multirow{2}{*}{ Axial } & Inner surface & \multirow{2}{*}{ Axial } \\
\hline & Crown & & Crown & \\
\hline \multirow{2}{*}{ Extrados } & Inner surface & \multirow{2}{*}{ Axial } & Inner surface & \multirow{2}{*}{ Axial } \\
\hline & Crown & & Crown & \\
\hline \multirow{2}{*}{ Crown } & Inner surface & \multirow{2}{*}{ Axial } & Inner surface & \multirow{2}{*}{ Axial } \\
\hline & Crown & & Crown & \\
\hline \multirow{2}{*}{ Intrados } & Outer surface & \multirow{2}{*}{ Hoop } & Outer surface & \multirow{2}{*}{ Hoop } \\
\hline & Crown & & Crown & \\
\hline
\end{tabular}




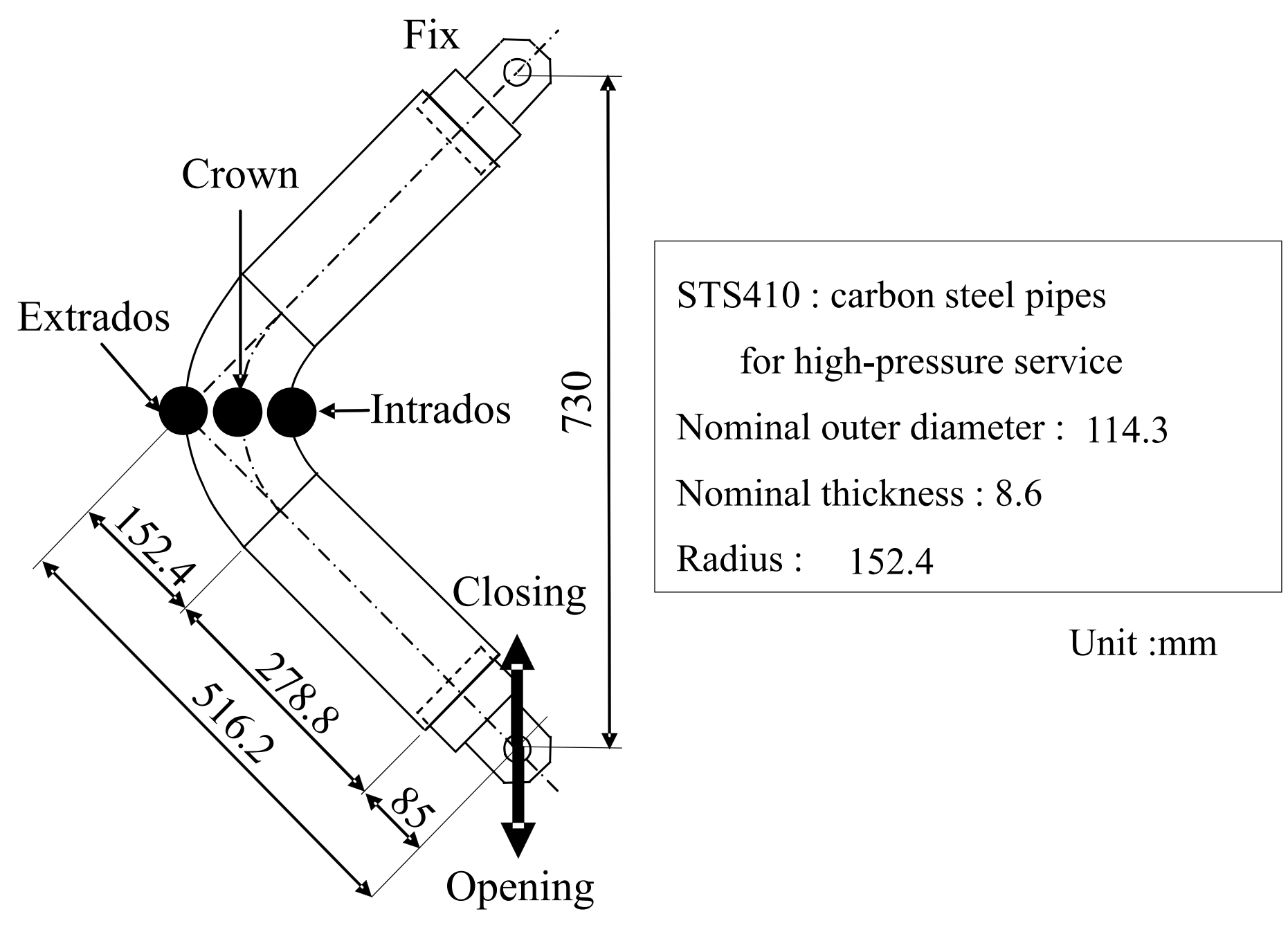

(a) Elbow specimen

Fig.1 Shape and geometries of elbow pipe specimen undergoing local wall thinning. (a) Elbow specimen,

(b) Detail of local wall thinning. 


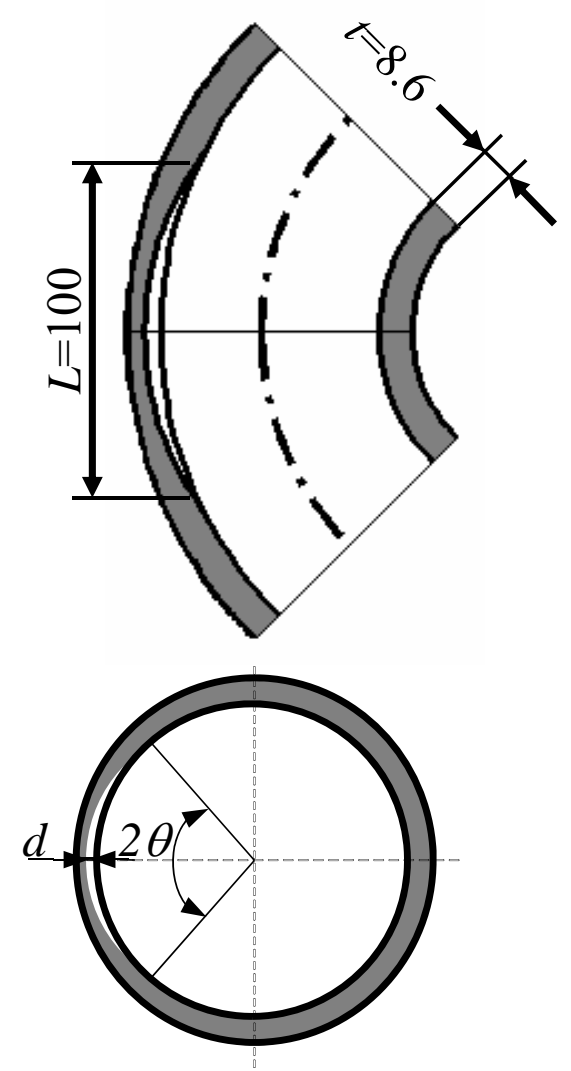

Extrados

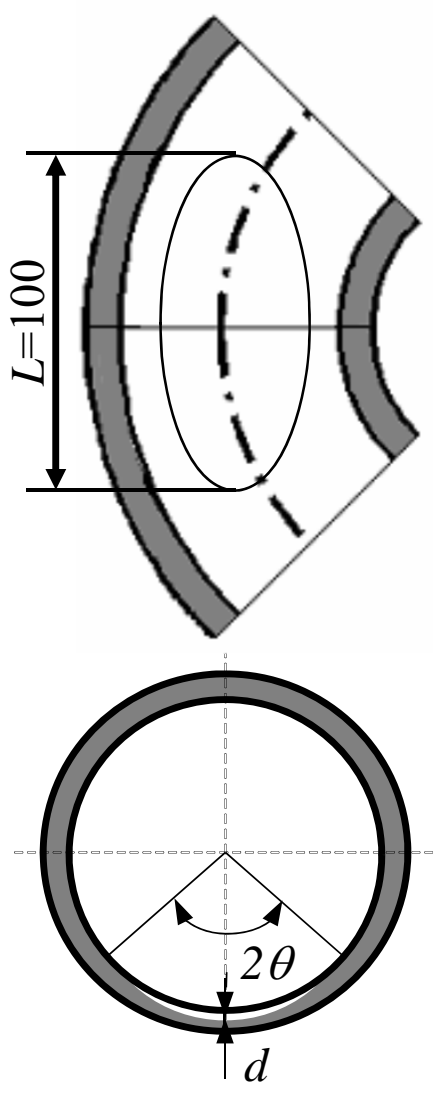

Crown

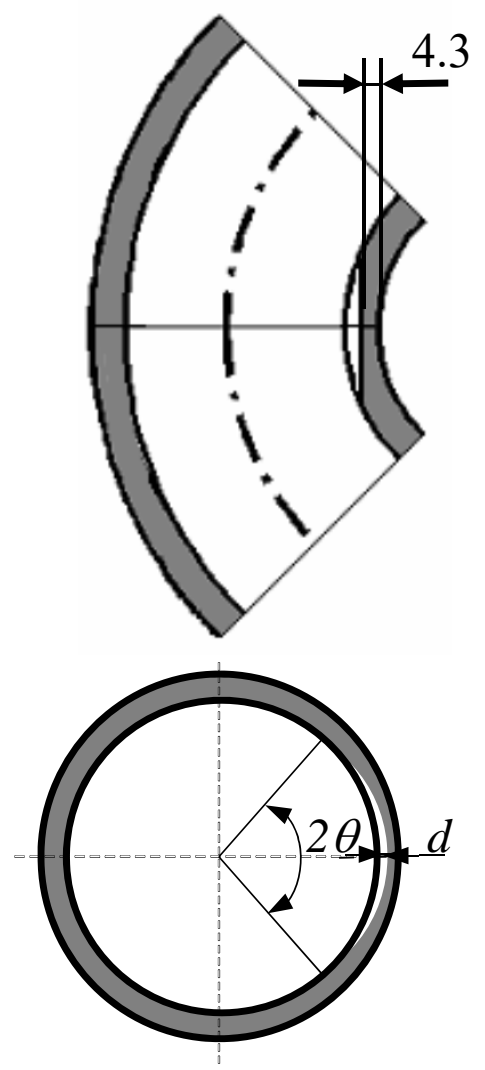

Intrados

Unit : mm

(b) Detail of local wall thinning

Fig.1 Shape and geometries of elbow pipe specimen undergoing local wall thinning. (a) Elbow specimen, (b) Detail of local wall thinning. 


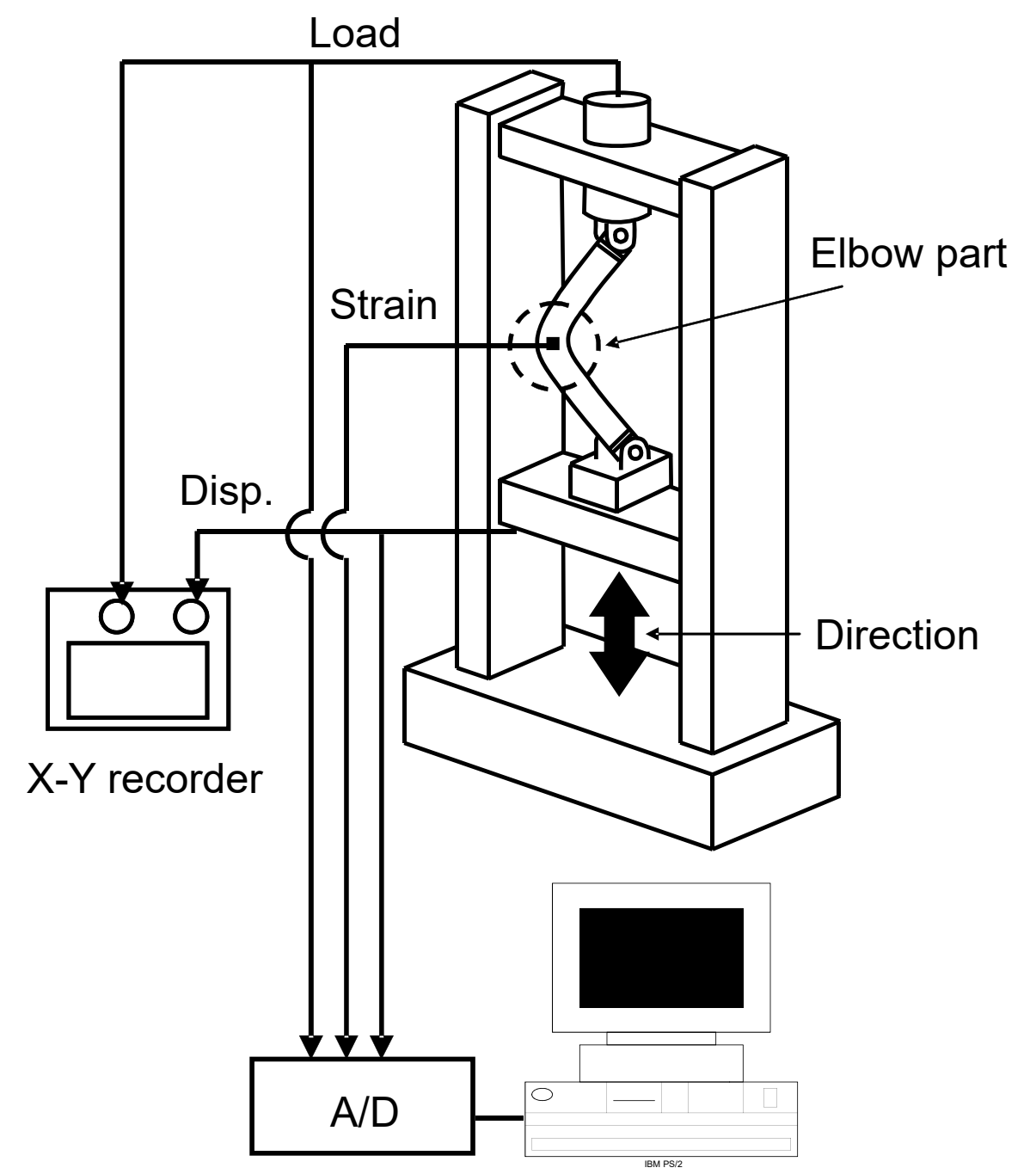

Fig.2 Experimental apparatus and elbow specimen. 


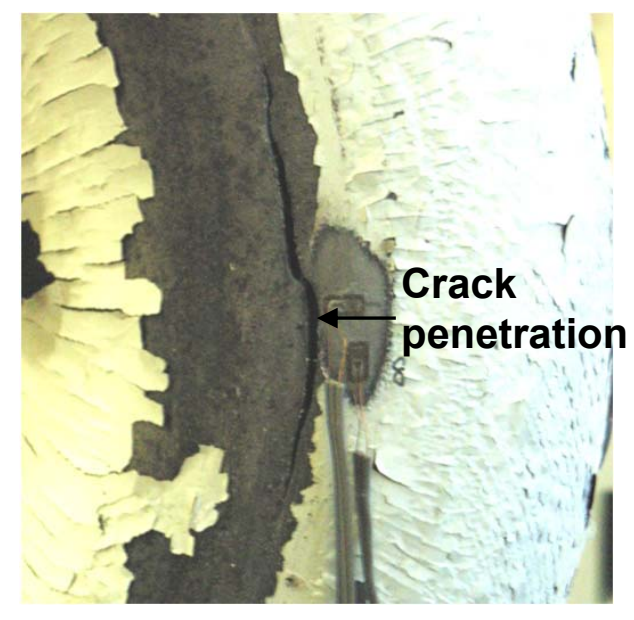

(a) Crown at $N=87$

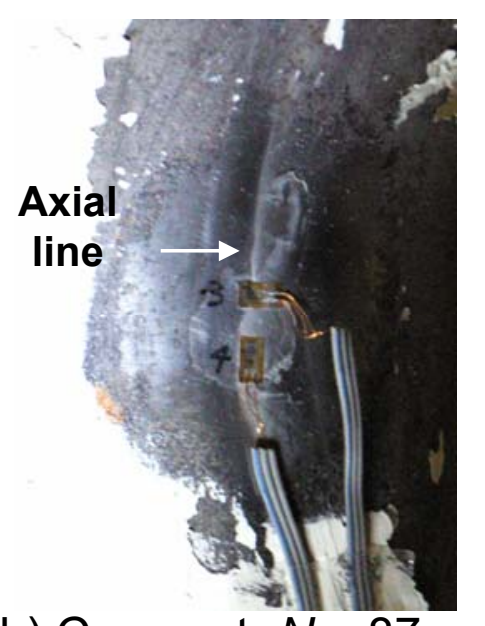

(b) Crown at $N=87$, opposite to (a).

Fig. 3 Crack penetration behavior in sound specimens $\left(N_{f}=87\right)$. 


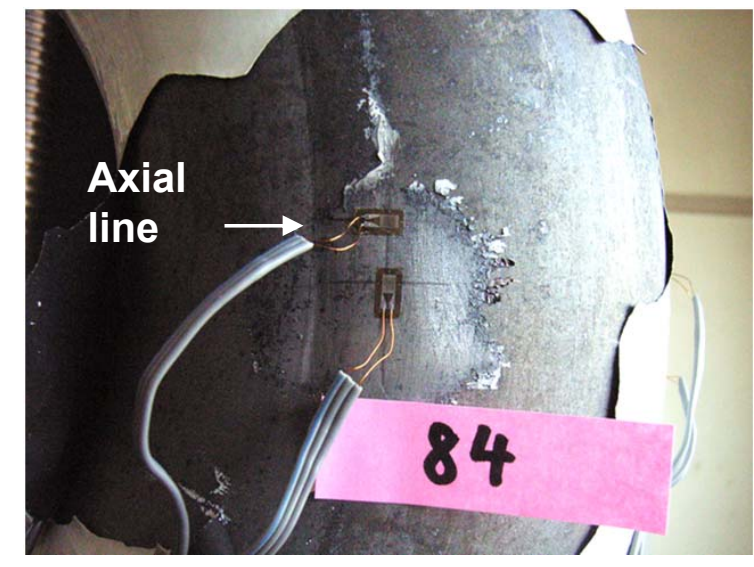

(a) Crown at $N=84$.

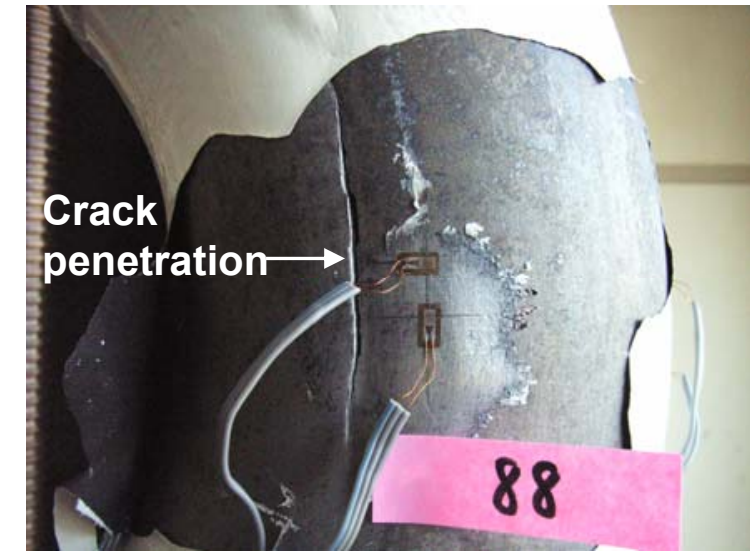

(b) Crown at $N=88$.

Fig. 4 Crack penetration behavior in extrados specimens $\left(N_{f}=88\right)$. 


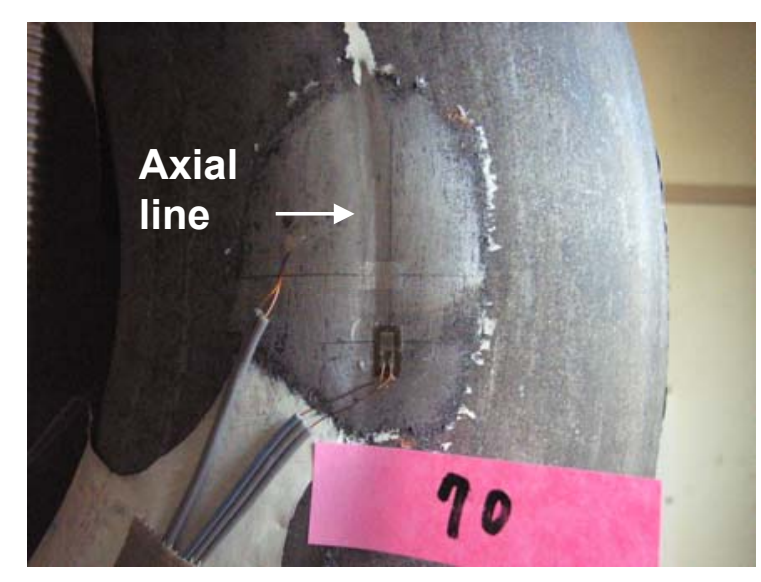

(a) Crown at $N=70$.

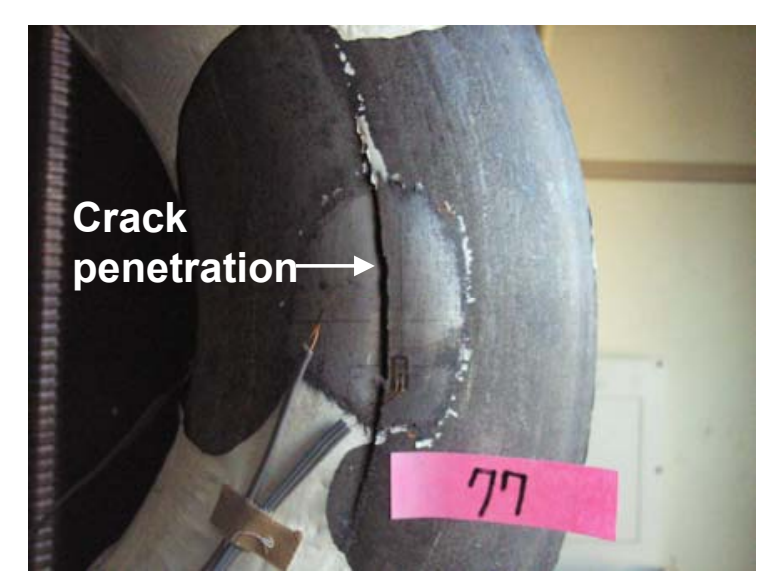

(b) Crown at $N=77$.

Fig. 5 Crack penetration behavior in crown specimens $\left(N_{f}=77\right)$. 


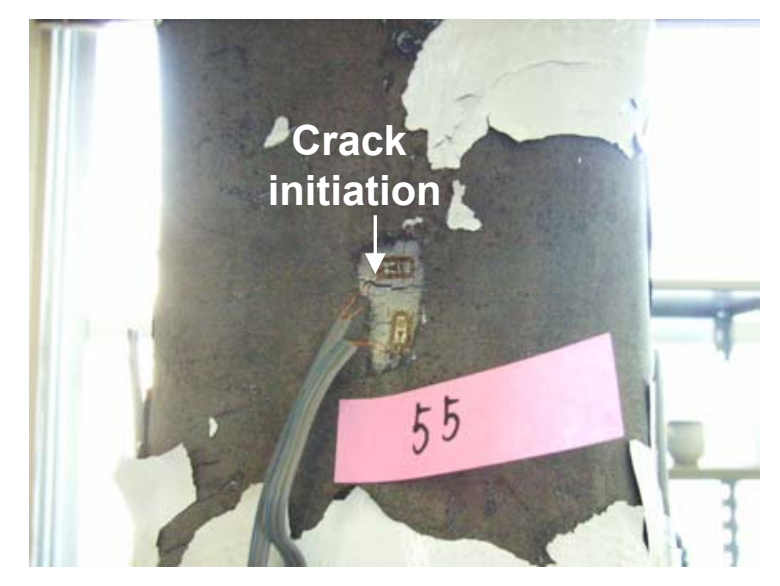

(a) Intrados at $N=55$.

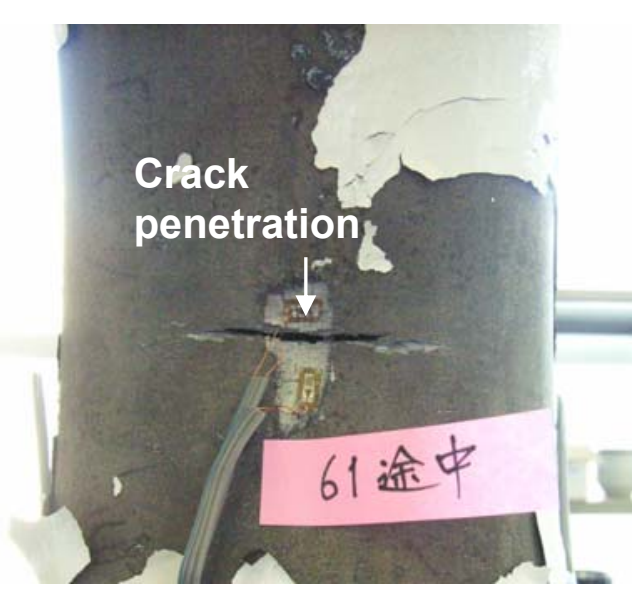

(b) Intrados $N=61$.

Fig. 6 Crack penetration behavior in intrados specimens $\left(N_{f}=61\right)$. 


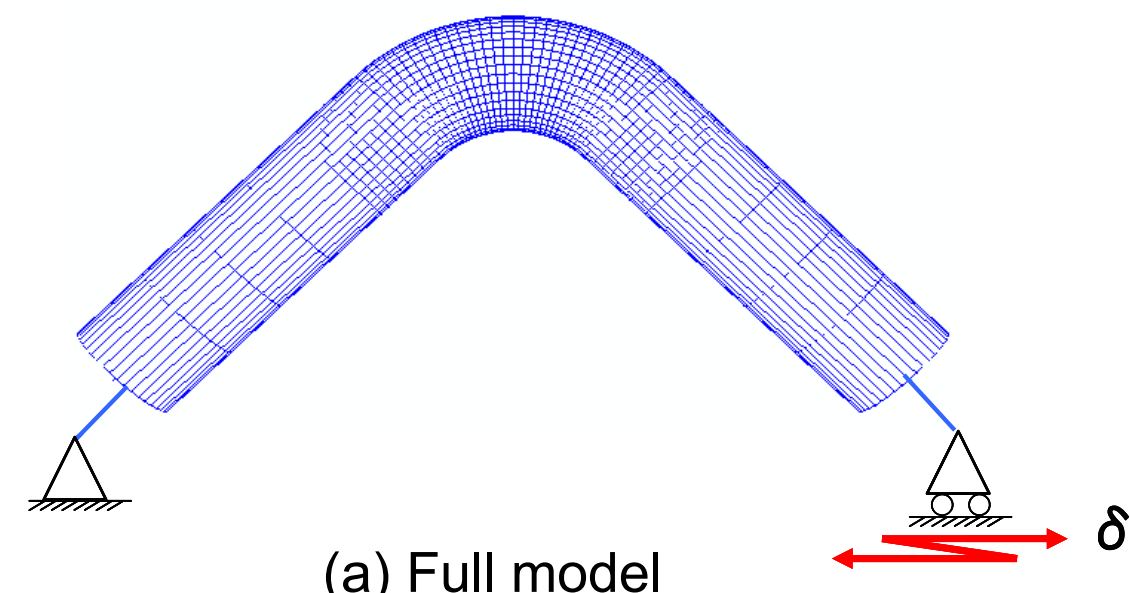

(a) Full model

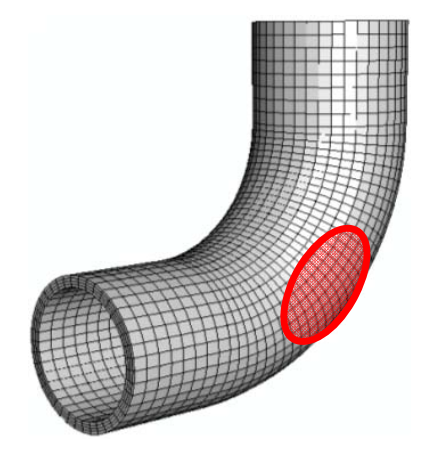

(c) Crown

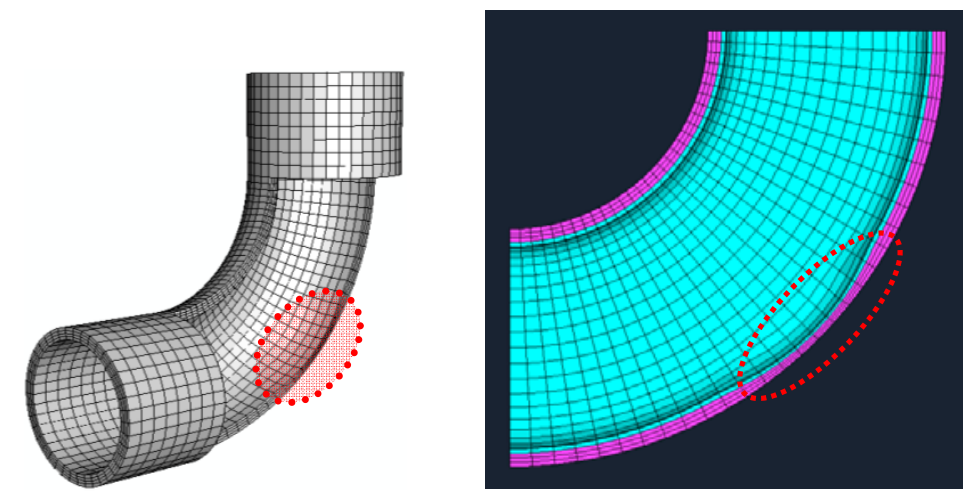

(b) Extrados

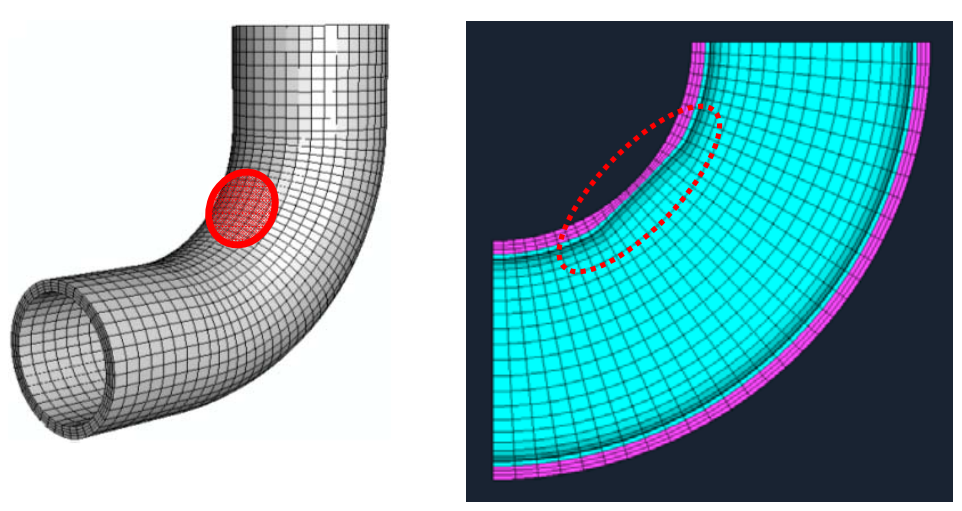

(d) Intrados

Fig.7 Finite element model of elbow pipe and eroded area. 


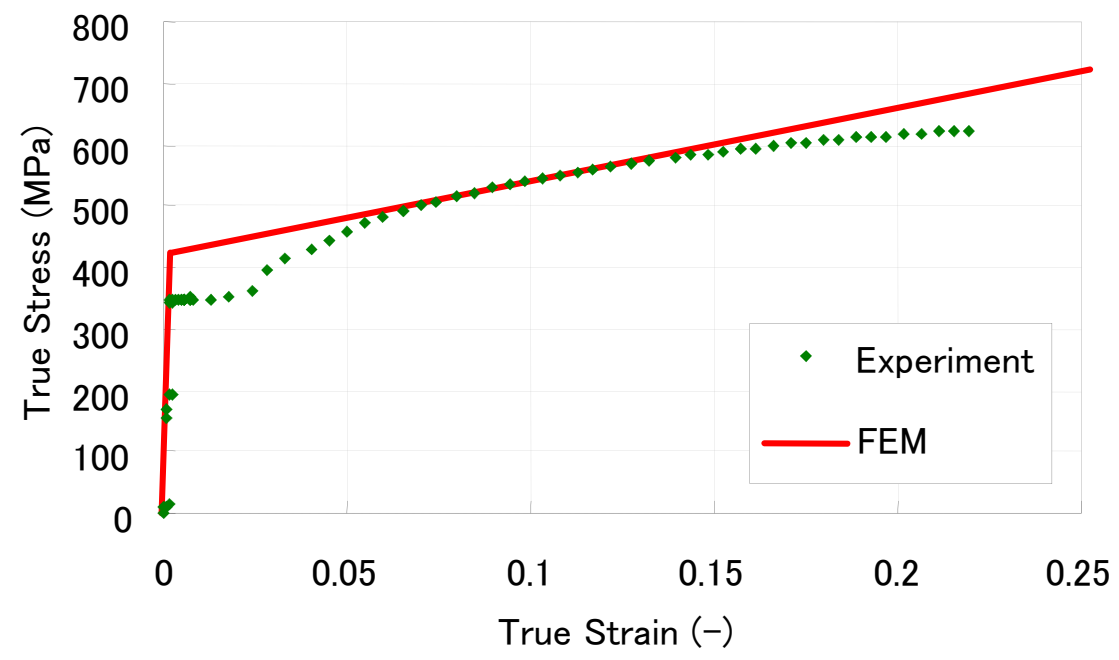

Fig. 8 Stress-strain curve for FE analysis. 


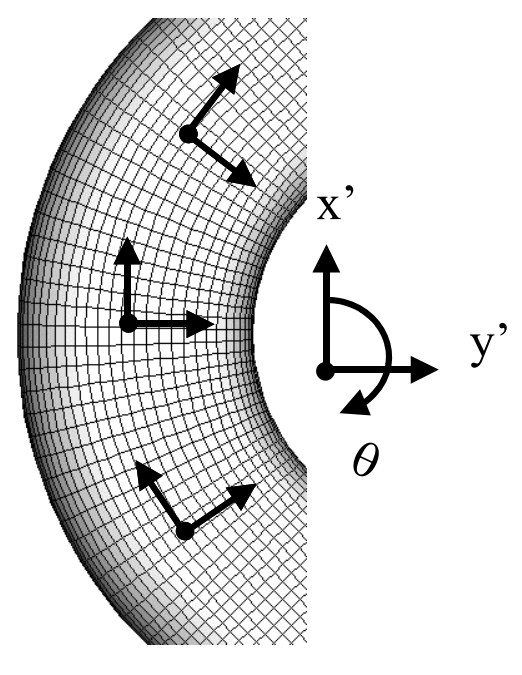

Fig.9 Local coordinate. 


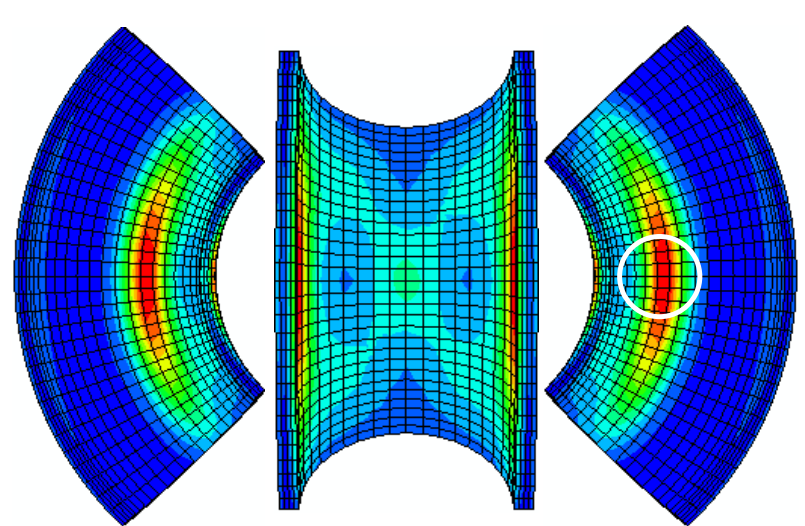

(a) Sound specimen (inner surface).

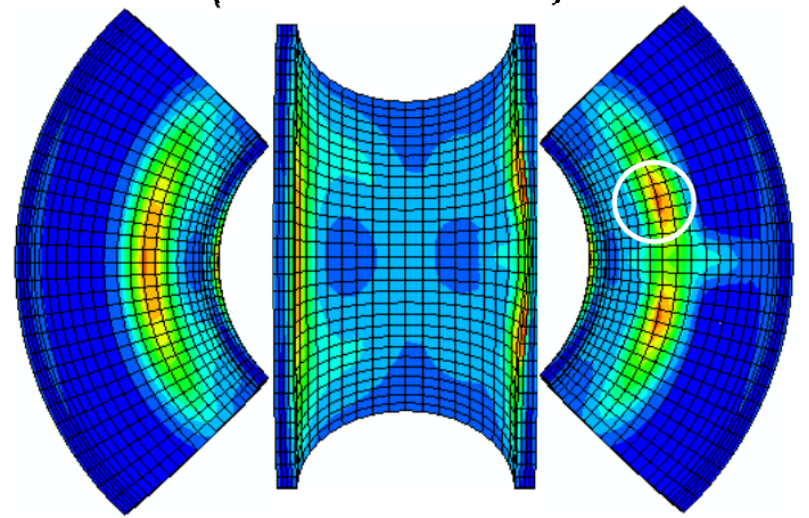

(c) Crown specimen (inner surface).

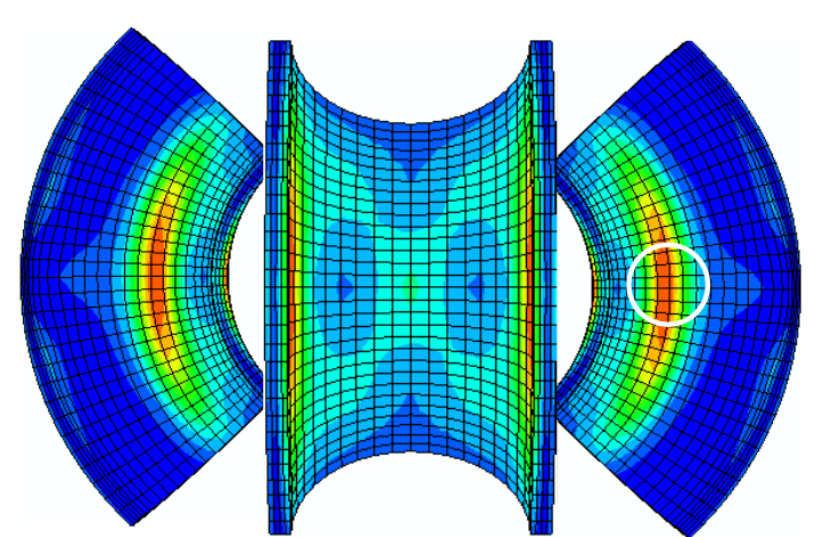

(b) Extrados specimen (inner surface).
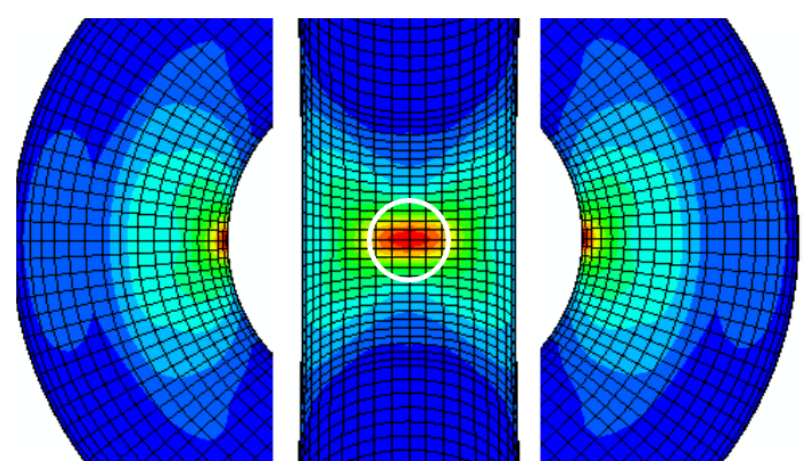

(d) Intrados specimen (outer surface).

Fig.10 Contour figure of equivalent plastic strain. 

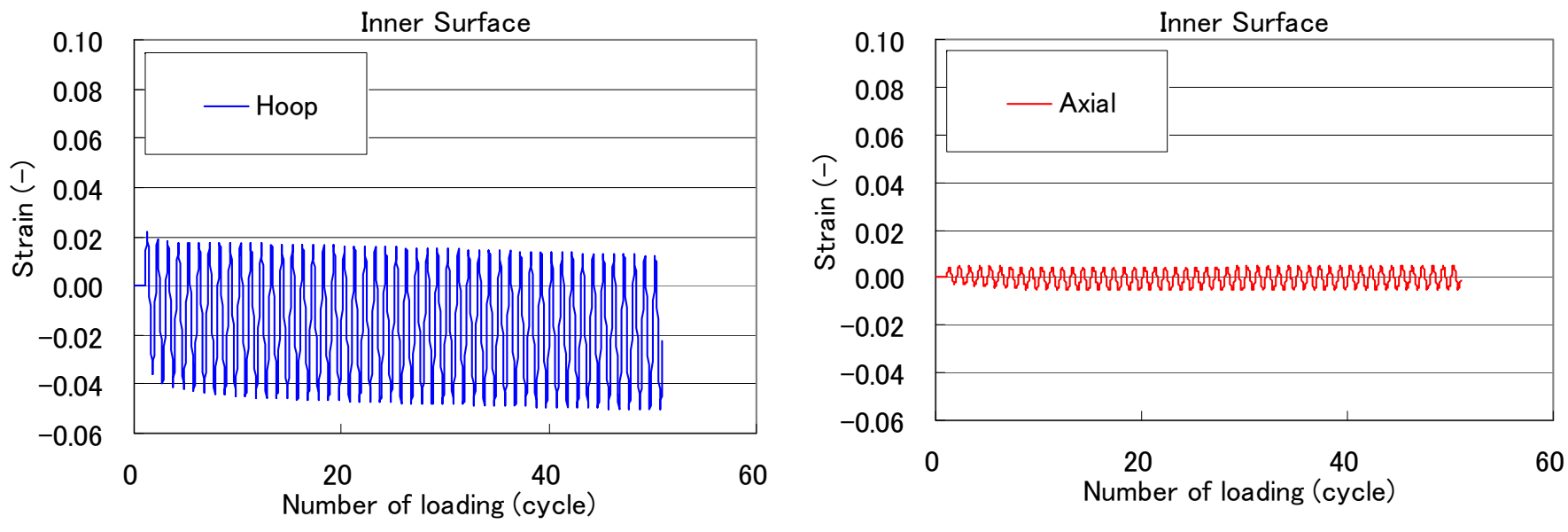

(a) Sound specimen (inner surface).
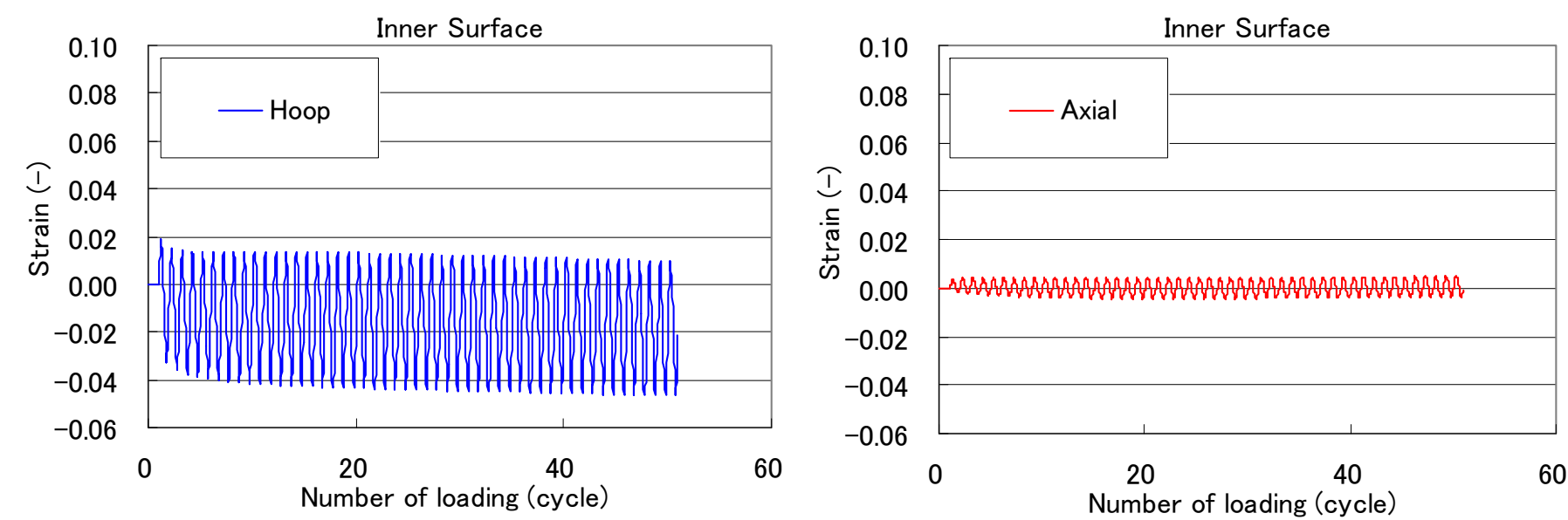

(b) Extrados specimen (inner surface).

Fig.11 Strain history at the most strain-concentrated point. 

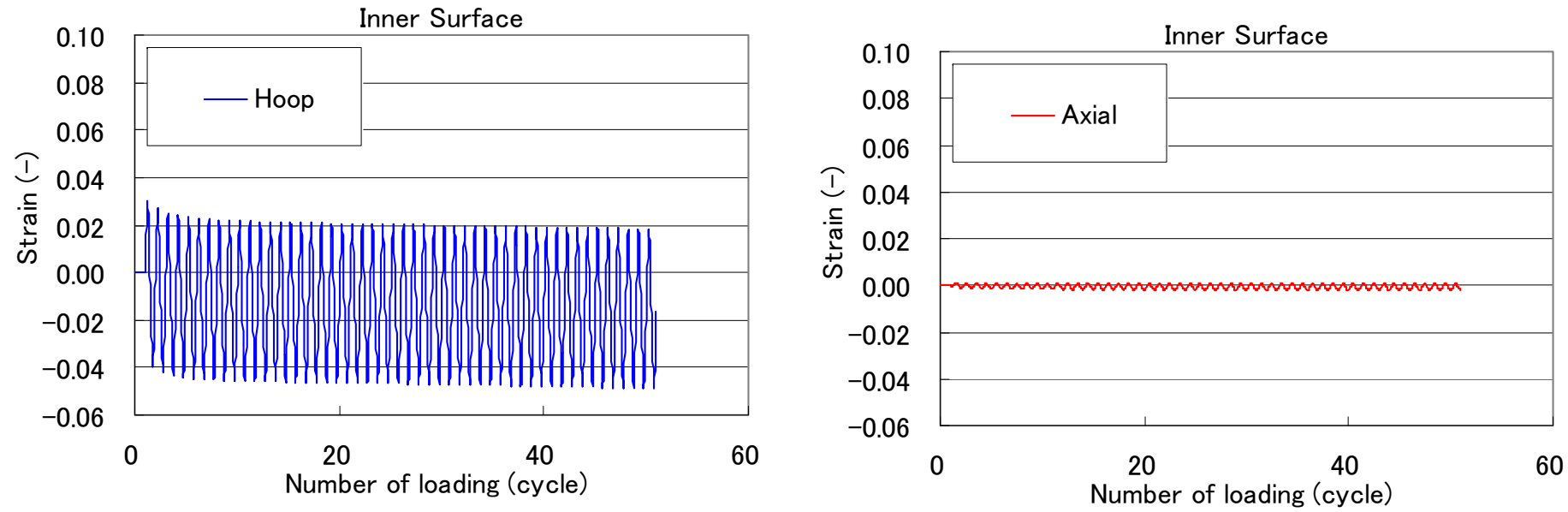

(c) Crown specimen (inner surface).
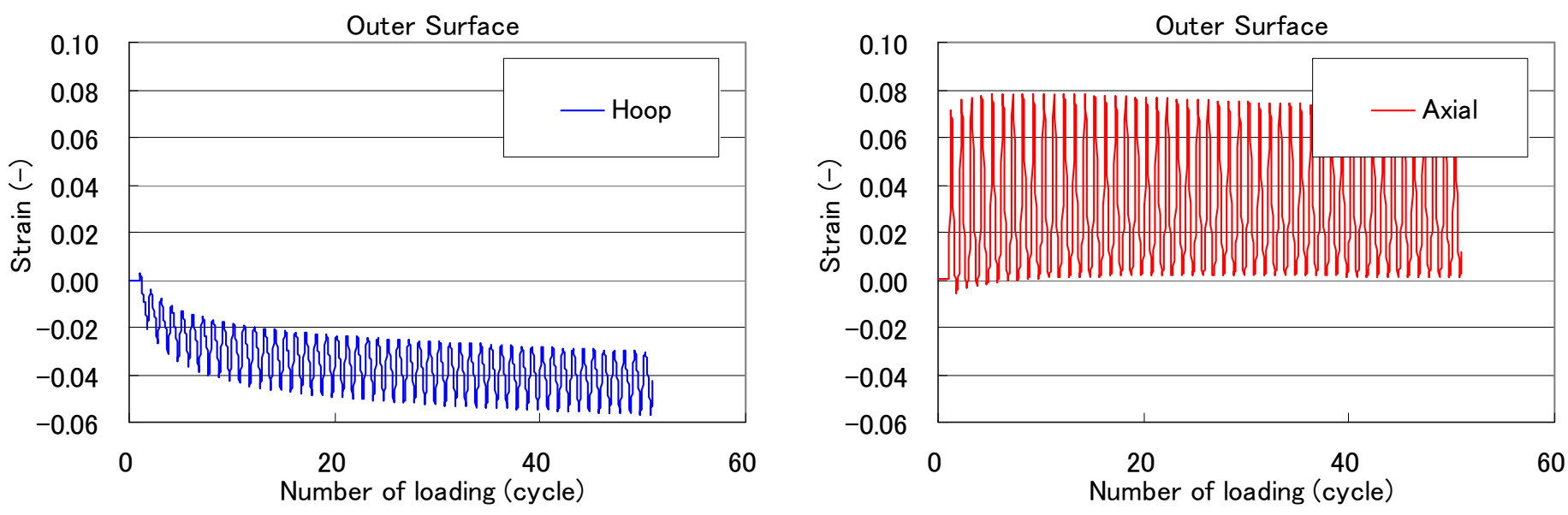

(d) Intrados specimen (outer surface).

Fig.11 Strain history at the most strain-concentrated point. 

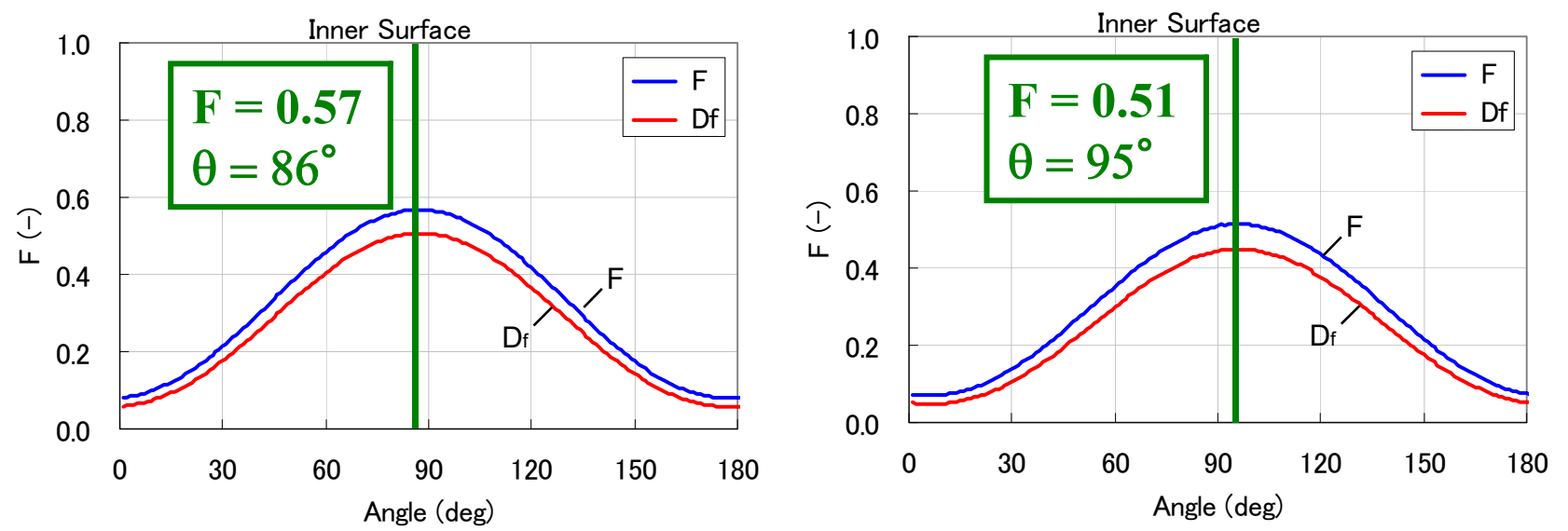

(a) Sound specimen (inner surface).

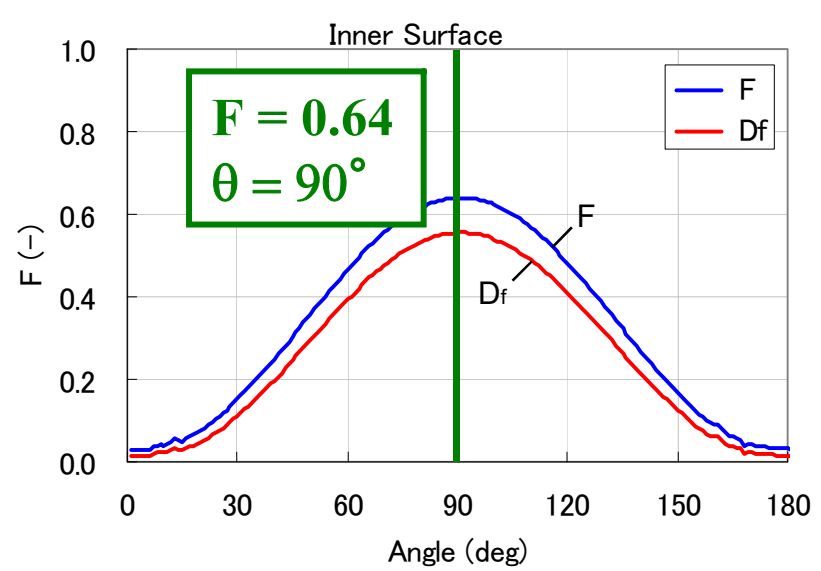

(c) Crown specimen (inner surface).

(b) Extrados specimen (inner surface).

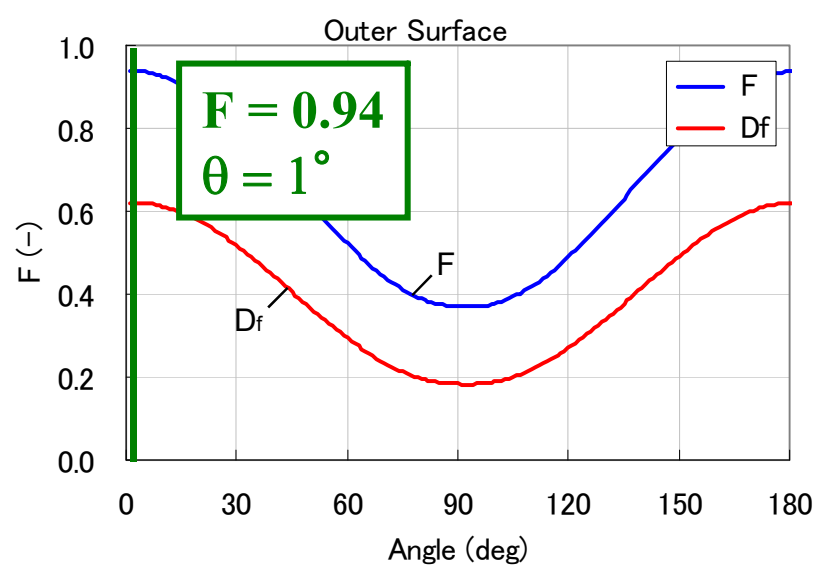

(d) Intrados specimen (outer surface).

Fig.12 Low-cycle fatigue factor $(F)$ at the most strain-concentrated point for 50 cycles. 


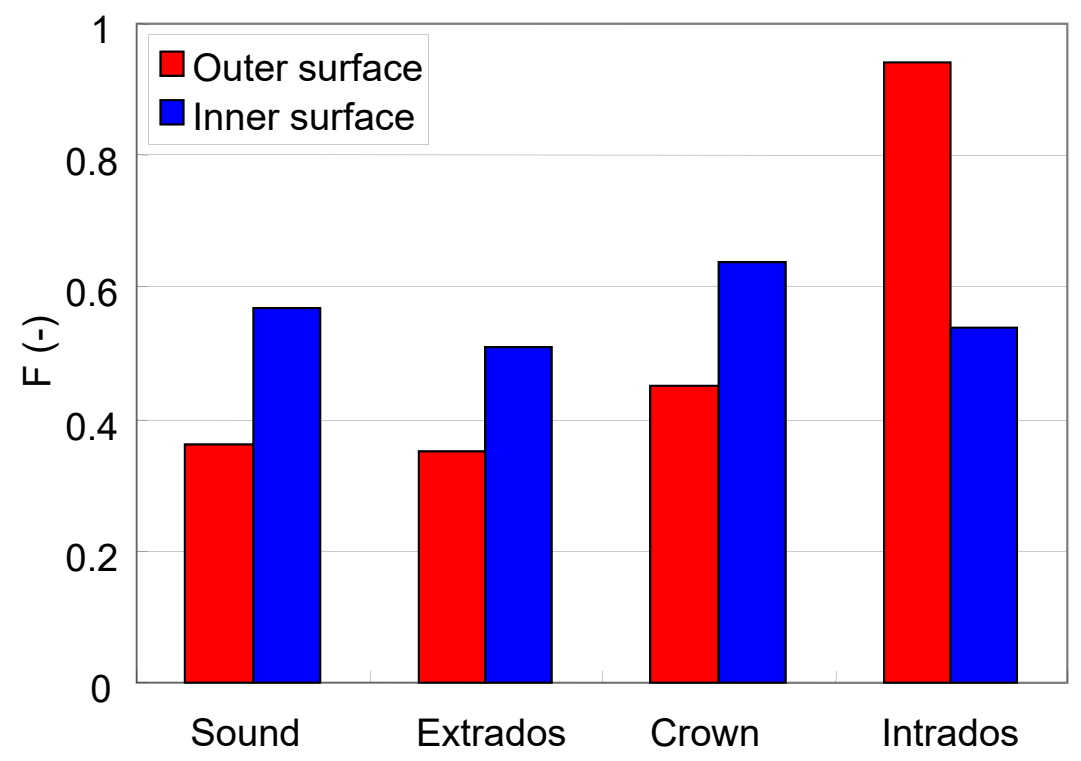

Fig.13 Comparison of low-cycle fatigue factor $(F)$ for 50 cycles. 


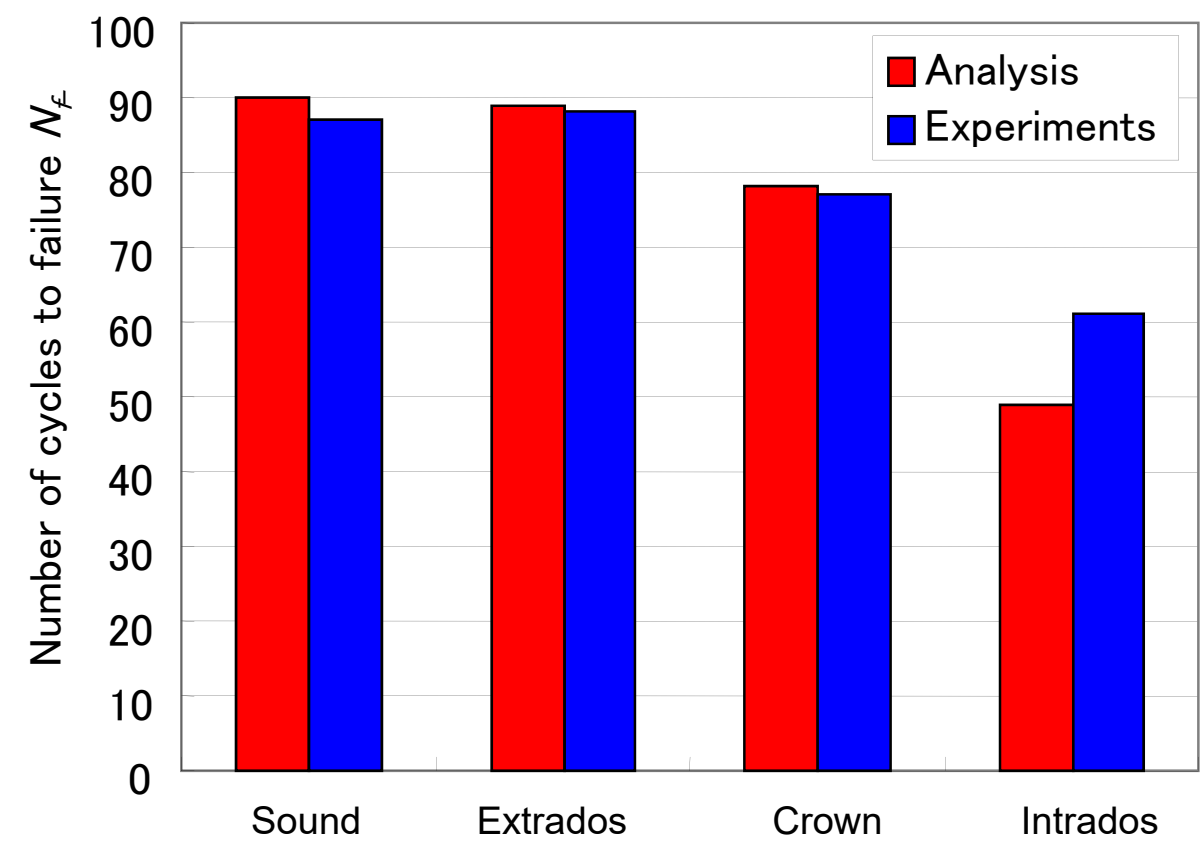

Fig.14 Number of cycles to failure in experiments and analysis. 